\title{
Figuras de santidad en el virreinato de Perú: lo queer, la alteridad*
}

Sainthood Figures in the Viceroyalty of Peru: Queerness, Otherness

Pilar Espitia Durán ${ }^{\mathrm{a}}$

Pontificia Universidad Javeriana, Colombia

DOI: https://doi.org/10.11144/Javeriana.cl25.fsvp

pespitia@javeriana.edu.co

ORCID: https://orcid.org/0000-0001-9061-0846

Recibido: 29 abril 2019

Aceptado: 29 julio 2019

Publicado: 13 octubre 2020

\section{Resumen:}

La santidad y sus manifestaciones son un tema que se vuelve primordial en los estudios culturales de la colonia latinoamericana: es a través de la construcción de figuras de santidad que identificamos los deseos sociales y diversas tensiones étnicas, de clase y de género, y también podemos encontrar espacios fluidos y de hibridez. Este ensayo, que forma parte de mi disertación doctoral, expone la santidad católica en el virreinato de Perú a través de los casos de Santa Rosa de Lima y San Martín de Porras. Al estudiar el misticismo, propongo pensar las figuras de santidad como sujetos queer, es decir, como sujetos que retaban, alteraban y cuestionaban las estructuras coloniales.

Palabras clave: santo, colonia, género, misticismo, religión, queer.

\section{Abstract:}

Sainthood and its manifestations are a subject that has become fundamental when doing cultural studies of the colony in Latin America; it is through the construction of saintly figures that we can identify social desires and diverse ethnic, class and gender tensions, but we can also encounter much more hybrid and fluid spaces. This essay, part of my doctoral dissertation, presents catholic sainthoods in the Viceroyalty of Peru, through the cases of Santa Rosa de Lima and San Martín de Porras. By studying mysticism, my proposal aims to think saintly figures as queer subjects, that is to say, as subjects who challenged, altered and questioned colonial structures.

Keywords: Saint, colony, gender, mysticism, religion, queer.

Hacia finales de siglo XVI, Lima, o la Ciudad de Los Reyes, podría considerarse desde la mirada deseante de la península como una típica ciudad colonial del Imperio español en América, que estaba en todo el clímax de su esplendor: las instituciones del imperio parecían funcionar de acuerdo con la máquina del poder. En Lima y sus alrededores parecía haberse llevado a cabo una aparente y exitosa evangelización, y el sometimiento de los indígenas a los estatutos coloniales. No obstante, la Lima de aquella época era mucho más compleja de lo que se quería aceptar, y era innegable la transculturación que se llegó a vivir durante la época: indígenas, africanos, españoles y mestizos convivían de manera fluida, lejos de la segregación aparente que quería mantener a raya todo contacto entre las distintas etnias y clases sociales de la ciudad:

Para el siglo diecisiete, Lima era una ciudad multiétnica y lejos de la segregación. La población española, india y africana se mezclaba en plazas, iglesias, mercados, calles y callejones [...]. En su análisis económico y social sobre la población indígena permanente en Lima en 1613, Paul Charney (1988) demuestra la presencia económica y política de una activa minoría indígena de casi 2000 personas [...]. Adicional a las poblaciones indígenas y españolas, la Lima colonial también contenía una gran población africana de aproximadamente 10.300 personas, que consistía en algunos negros libertos, y muchos otros esclavos de África y de otras colonias hispanoamericanas (Bowser 1974). Para ser breves, parece claro que los llamados barrios segregados de la capital no eran más que las sombras de un intento fallido de las autoridades coloniales por implementar en Lima una sociedad colonial idealizada (pero en este caso, imposible), de dos "repúblicas" segregadas, una española y otra indígena, con espacios adicionales para esclavos o mestizos. (Osorio 198-199)

Notas de autor

a Autora de correspondencia. Correo electrónico: pespitia@javeriana.edu.co 
Por un lado, no era cierto que la colonización y evangelización hubieran permeado todo de manera homogénea y efectiva. De hecho, hacia finales de 1609 se establece un movimiento oficial de extirpación de idolatrías, liderado por el párroco de Huarochirí, Francisco de Ávila, quien consideraba que sus feligreses aún no eran plenamente cristianos. Esto reflejaba las enormes sospechas por parte de las autoridades de que todavía existía un manto de idolatría cubriendo los territorios conquistados, y que los locales seguían honrando a sus dioses nativos. Por otro lado, y a pesar de la deseada segregación para la ciudad de Lima, esta comenzó a presenciar "extrañas" prácticas espirituales místicas, muchas veces llevadas a cabo por mujeres, y que para un imaginario contemporáneo e incrédulo resultarían simplemente imposibles, fantásticas o sintomáticas de una patología mental moderna.

En Lima, se escuchaban historias de mujeres que decían "volar" sobre la ciudad gracias a sus raptos divinos; piadosas que se entrevistaban con las almas del purgatorio; iluminadas que decían hacer milagros, curar enfermos y tener diálogos con el panteón del mundo católico. Así nos habla Fernando Iwasaki de Inés de Velasco, española, cuyo mote era La Voladora, "por haber tenido, creído y escrito muchas revelaciones, éxtasis, raptos, coloquios con Cristo Nuestro Señor, con la Virgen Santísima, con santos y ángeles del cielo" (Iwasaki, "Mujeres al borde" 79). También se refiere a la beata María de Santo Domingo, trujillana, más conocida como La Dedos Pegados, "por tener esa imperfección física. Afirmaba que era castigadora de demonios, que había sacado del purgatorio tales y cuales almas" (Iwasaki, "Mujeres al borde” 79). Igualmente, está Isabel de Ormaza, "casada, natural de Lima, india, y que vestía traje de beata de Santa Gertrudis. La acusaron de fingir milagros, curar enfermos por medio de amuletos y decir que los ángeles la festejaban con serenatas" (Iwasaki, "Mujeres al borde" 79-80).

Para muchos contemporáneos de estas mujeres, las sospechas fueron inevitables; en la ciudad ya comenzaban a tomarse medidas radicales contra estos brotes de religiosidad por sus connotaciones heréticas, pero también hubo muchos eclesiásticos de diferentes órdenes religiosas que defendieron estas devociones como casos legítimos de santidad en América. A su vez, no hay que olvidar que todas estas mujeres, muchas veces condenadas por “embuste o falsedad mística” frente a la Inquisición, también fueron cobijadas por ese velo de religiosidad ortodoxa que cubría a la ciudad de Lima: la abundancia de conventos, iglesias y religiosos hacían de la capital del virreinato peruano una "máquina de santos" (Estenssoro 482), ciudad-convento muchas veces representada como un jardín para cultivar la piedad católica. Tampoco hay que olvidar que todo este microcosmos de santidades femeninas eran mujeres cercanas a la famosa primera santa de América, Santa Rosa de Lima (1586-1617), y que otro contemporáneo, probablemente conocido por este mismo grupo de mujeres, sería el primer santo afroamericano de América: San Martín de Porras (1579-1639).

De acuerdo con esto, me gustaría plantear varias preguntas que iré tratando de responder en este texto: ¿Cuáles eran los límites - si es que existían - entre la ortodoxia y la heterodoxia? ¿Cómo fue posible que una mujer como Santa Rosa llegara a los altares de los santos con tanta facilidad, mientras que sus amigas en la fe quedaron relegadas a los archivos de la Inquisición? Igualmente, ¿cómo es que un mulato y personaje marginado como San Martín de Porras alcanzaría tanta fama y sería venerado como santo a lo largo de su vida y muerte? Y, finalmente, ¿qué implicaba ser una figura de santidad en la colonia y también seguir una espiritualidad que no estaba necesariamente ligada a la institucionalidad de la Iglesia? Para poder acercarme de una manera mucho más eficiente a tales planteamientos, me gustaría explicar lo que significaba tener una espiritualidad de corte místico, lo que me llevará también a proponer una lectura de las figuras de santidad como identidades queer.

\section{Lo místico, lo queer}

El misticismo, por su complejidad y elementos que trascienden la lógica racional y la palabra, es una forma de espiritualidad que es difícil de definir. Ya lo había constatado Michel de Certeau, uno de los grandes estudiosos 
del misticismo, cuando intentó explorar, en La fábula mistica: siglos XVI-XVII, el misticismo desde varios ángulos, y terminó por entender que era una materia imposible de asir. Sin embargo, podríamos plantear lo místico de una manera muy general como un discurso amable de y sobre Dios, y que revela una relación individual e íntima con la figura divina. Por lo mismo, la peligrosidad en este tipo de expresión religiosa es que no requiere de la intervención de la iglesia y sus rituales institucionales para hacerse posible. De hecho, el misticismo como práctica espiritual fue una de las mayores causas de oposición por parte de la Iglesia católica a la Iglesia luterana en Europa y lo que impulsó la Contrarreforma. De acuerdo con esto, ¿̀hasta qué punto la Iglesia católica aceptaba o incluso promulgaba este tipo de religiosidad no solo en Europa, sino también en las colonias americanas?

La Iglesia en Europa no era ajena a este tipo de luchas y, por ejemplo, para el caso de España, entre 1510 y 1512, ya se habían hecho seguimientos a los proclamados "alumbrados" o "erasmistas", que eran movimientos surgidos gracias a la reforma luterana. Por un lado, eran movimientos que se oponían a los sacramentos y prácticas comunitarias de la Iglesia, pero, por otro lado, este tipo de prácticas también involucraban actos o rituales sexuales. De acuerdo con esto, las prácticas místicas tenían una fuerte carga erótica, y, desde la lectura de Certeau, esta espiritualidad había desplazado al amado del amor cortés, para llegar a un Amado cuerpo de Cristo- hecho divinidad (Certeau 14). En el misticismo, las prácticas de autodesprecio, ayuno, disciplinares y sacrificiales conllevan a la alegre posibilidad de encontrarse con el Amado en desposorios místicos y llegar así a estados de arrobamiento; las descripciones de tales estados son unas de ebriedad y gozo que rozan con lo que podríamos encontrar en otros textos de carácter erótico y sexual.

Las implicaciones que puede traer este postulado son grandes y generarán una discusión fructífera en cuanto a los estudios de género, el sexo, el feminismo, las masculinidades y la mística misma: ¿qué pasa, por ejemplo, cuando la experiencia mística es la de una mujer y no la de un hombre, y cómo se genera ese discurso amoroso frente al ser amado que es Dios? ¿Qué implicaciones tiene que ahora sea la dama la que hable del amor (ya no es más el objeto de deseo o la excusa del poeta) y cómo se produce este lenguaje que estaría por fuera de la rigidez masculina del lenguaje teológico? ¿Habría una inversión de los papeles femeninosmasculinos o, más bien, una reinvención no solo del sujeto en sí, sino del Amado? ¿Ahora, qué pasa cuando el místico es un hombre y qué relación tendría con el Amado, que es finalmente la figura de Cristo? ¿Acaso en esta propuesta y desarrollo del misticismo no estaríamos ya viendo un tipo de erotismo que rompe con los esquemas binarios, heteropatriarcales, y en el que se ofrece una erótica queer?

Creo que es necesario explicar aquí a lo que me refiero con queer, pues puede, en principio, ser un término que puede escandalizar a unos cuántos, y más al ser usado en el contexto de la santidad. Cuando me refiero a una erótica o identidad queer, me refiero a unas prácticas que rompen con los modelos heteronormativos, y que se mueven en varias zonas grises de la identidad, tal y como lo han definido Annamarie Jagose, Judith Butler o David Halperin, grandes teóricos de lo queer:

Para Halperin, y también para Butler, lo queer es una manera de apuntar hacia adelante sin tener certeza de a qué se apunta [...]. Lo queer es siempre una identidad bajo construcción, un lugar permanente de transformación [...]. El alcance que le han dado los diferentes teóricos al potencial desconocido de lo queer sugiere que una de sus características más propicias debe ser su potencial para ver hacia adelante sin anticiparse hacia el futuro. (Jagose 131; traducción propia)

De acuerdo con esto, afirmaría que, en efecto, la erótica y las identidades producidas por una espiritualidad como el misticismo son queer y rompen con una propuesta heteronormativa que proviene de las tradiciones amorosas, como el amor cortés, y de una corriente religiosa, con El Cantar de los Cantares. Como lo propone Karma Lochrie al reflexionar sobre el misticismo en la Europa medieval: "El sexo místico no es solo 'el sexo como lo conocemos', sino un campo mucho más problemático de la experiencia que se desvía hacia las esferas de la violencia, el sufrimiento y la tortura” (Lochrie 183; traducción propia). Así, el cuerpo del místico es el centro de la experiencia espiritual y este cuerpo es posible en la medida en que es uno sufriente y adolorido. La penitencia y negación que sufre el cuerpo es el medio para poder acercarse a la espiritualidad y al ser amado; hay una sintomatología (el cuerpo herido por la flecha del amor) que se hace presente en el cuerpo místico 
y que representa el sufrimiento voluntario a través de ayunos, estigmas, enfermedades, etc., para alcanzar un nivel de comunicación espiritual con Dios. Esta relación oscura entre el sufrimiento y la tortura, para encontrar el placer y el amor, sería una de las formas en las que el misticismo moldea una erótica queer y en la que incluso cualquier binomio de géneros y sexualidades quedaría disuelto.

Además, la imitación de Cristo en el misticismo es central, y el papel principal del místico consiste en asumir e imitar el cuerpo del Amado: se quiere construir-destruir un cuerpo que imite al hijo de Dios y que tome un lugar sacrificial. Pero, a menudo, cuando se ha llegado a un lugar privilegiado y el Amado acepta el amor del místico, se halla una inversión de roles y vemos frecuentemente a la mujer mística jugando un papel varonil y empoderado, mientras que Cristo asume un papel infantil o feminizado. En el caso de las figuras místicas masculinas, llegaríamos incluso a leer cierto homoerotismo; místicos como San Juan de la Cruz se han definido a sí mismos como la Esposa de Cristo.

Ahora bien, al añadir a estas experiencias místicas queer el contexto de la colonia americana, nos encontramos con una doble complejidad: primero, las prácticas de misticismo o de una espiritualidad individual sembraban en la Iglesia una gran sospecha y, por eso, muchas de estas mujeres u hombres místicos eran vigilados de cerca por sus confesores. Estos últimos exigían a través de la confesión varios detalles acerca de las prácticas que llevaban, de modo que no hubiera escape a la ortodoxia. Asimismo, los confesores tenían la obligación de denunciar ante la Inquisición cualquier práctica que no fuera considerada como fiel a la Iglesia. En segundo lugar, el hecho de que las prácticas místicas tuvieran lugar en territorios relativamente neófitos en la fe harían que la persecución fuera mucho más intensa.

Si en España los primeros místicos o iluminados fueron perseguidos principalmente por sus prácticas heterodoxas, por erasmistas o por ser criptojudíos, en la colonia había otro tipo de preocupaciones. A las sospechas por heterodoxia, se sumaron dos fuertes inquietudes: que las prácticas religiosas indígenas permearan las estructuras religiosas católicas y que, además, las prácticas de misticismo no fueran auténticas, o que fueran la emulación de algo que no era "real". La doble ansiedad de la Iglesia católica de erradicar las prácticas nativas a través de la evangelización y de encontrar a como diera lugar una representación legítima de la santidad en América generaba también conflictos para la institucionalidad misma, pues esto implicaba poder aceptar casos de santidad y misticismo sin más, en un Nuevo Mundo donde la idolatría de los indígenas continuaba siendo una amenaza real para el catolicismo: "Los miembros de la Iglesia mezclaban sus ansiedades sobre la espiritualidad popular incontrolable y la adoración a los santos con los miedos de las posibles influencias de tradiciones religiosas indígenas del Nuevo Mundo sobre la población no indígena” (Jaffary 43; traducción propia).

En ese sentido, la preocupación de las prácticas místicas en América se enfocó más en la legitimidad o no de las mismas, como lo discute Nora Jaffary en el caso de los místicos en Nueva España. En sus estudios, Jaffary nota que en los casos de la Inquisición contra místicos de la Nueva España se pasa de utilizar el término alumbrado, a utilizar con más frecuencia términos como iluso, engañador, embaucador e hipócrita. Nos dice Jaffary que

la valoración de la autenticidad mística de un individuo se había alejado de la preocupación de detectar doctrinas disidentes particulares, más típicas de los juicios españoles. En el contexto mexicano, la detección del misticismo falso se enfocaba en una preocupación de perseguir individuos acusados de suplantar a otros [...]. Tres tipos de tensiones le daban forma a esta sociedad: el nacionalismo criollo en aumento, el crecimiento de la población mestiza y la erosión de la obediencia respetuosa a los agentes o dictámenes de la corona española y la Iglesia católica. En este ambiente, el crimen religioso del iluminismo la falsificación de la experiencia mística - era un reflejo del miedo de la sociedad elitista de que los miembros de la población colonial tuvieran la habilidad de engañar o hacerse pasar por alguien que no eran. (Jaffary 37; traducción propia)

Estos elementos de místico "verdadero" y místico "falso" traen a colación un paralelo entre las definiciones de este misticismo, su cuestionamiento de la legitimidad y lo que sería una naturalización de las identidades de género, en contraposición de una identidad queer que es desnaturalizada y está en constante construcción. Esto me permite establecer una nueva relación entre lo queer y los estudios del misticismo: si lo queer es un 
constante cuestionamiento y desestabilización del género, el sexo y las identidades naturalizadas, la identidad del místico también es una que se construye y destruye constantemente. En ese sentido, este tipo de identidad podría desnaturalizar a su propia sociedad y a sus intenciones de controlar la naturaleza de las prácticas religiosas. Además, el misticismo per se se define muchas veces a partir de la marginalización y la abyección: el místico es, al fin y al cabo, un diábolos de la comunidad, un sujeto que destruye y cuestiona los órdenes sociales, como lo menciona Certeau en su estudio sobre la mística.

De acuerdo con esto, una de las estrategias que utiliza lo queer para desnaturalizar las identidades y sexualidades definidas es la de reconocer el carácter de lo performativo dentro de la construcción de las identidades. Tal y como lo postuló Judith Butler en su obra emérita que dio paso al estallido de lo queer, Gender Trouble: Feminism and the Subversion of Identity, el género no es más que una repetición de comportamientos, es decir, un acto performativo: "El género es reconfigurado por Butler como una ficción cultural, un efecto performativo de actos reiterativos [...]. Como consecuencia, no hay nada auténtico acerca del género, no hay un 'núcleo' que produzca los signos reconfortantes del género" (Jagose 84; traducción propia).

En ese sentido, no habría ningún género sexual (ni, por lo tanto, una forma de ser místico) que fuera claramente natural, en contraposición a otro que resultara siendo una parodia o un desvío de la norma:

Como consecuencia, la heterosexualidad no puede ser asumida como el original en el que la homosexualidad es una copia inferior. Al defender la parodia como una estrategia de resistencia, Butler intenta demostrar que el dominio de los géneros y de la sexualidad no están organizados en términos de originalidad e imitación. En cambio, lo que manifiestan son las infinitas, aunque grandemente reguladas, posibilidades de la performatividad. (Jagose 85; traducción propia)

De acuerdo con esta noción de lo performativo y lo queer, mi propuesta sobre algunas figuras de santidad en la colonia española en América consiste en una lectura a contrapelo del misticismo y una reinterpretación de estas prácticas durante la colonia. Considero que lo queer, como una lente de interpretación, es una herramienta que enriquece el simbolismo de los místicos y nos permite ver que las figuras de santidad eran bastante complejas, que no solo cuestionaban las prácticas y tradiciones heteronormativas de la sociedad, sino que a través de su espiritualidad se reinventaban y lograban movilizarse socialmente. Esto lo podremos evidenciar en los casos ya mencionados que me propongo estudiar ahora: el de Santa Rosa de Lima y el de San Martín de Porras.

\section{Santa Rosa de Lima (1586-1617) o el microcosmos del deseo en la Lima colonial}

La Rosa de América — cuyo nombre real era Isabel Flores de Oliva_, criolla y beata de la ciudad de Lima, es tal vez el caso más estudiado de santidad del Perú: su rápido ascenso a la santidad, a solo 50 años de que muriera, hace de esta mujer un caso excepcional dentro de la burocracia quisquillosa de la Iglesia católica. Al mismo tiempo, se ha querido ver su proceso como uno bastante limpio y sin tropiezos: sus principales biógrafos, entre ellos el alemán y dominico Leonardo Hansen, intentan borrar cualquier duda sobre la santidad legítima de la santa, pero, al hacer una contralectura de este tipo de textos, y aprender sobre el contexto de la santa, veremos que la situación de Santa Rosa fue mucho más compleja de lo que se cree.

Por un lado, no podemos ignorar que la Rosa de América fue muy cercana a un grupo de mujeres que fueron condenadas por la Inquisición. Entre estas figura la famosa Luisa de Melgarejo, tunjana y casada con el doctor Juan de Soto, que se consideraba tan espiritual como Rosa, y que incluso sería la que le daría la fama a la santa, cuando, frente al cadáver de Santa Rosa, entró en un trance espiritual y confirmó que Rosa había ascendido de manera directa a los cielos. Al mismo tiempo, la famosa Luisa fue luego investigada por la Inquisición y todos sus escritos fueron decomisados, lo que inevitablemente nos hace cuestionarnos por qué la dicha Rosa tuvo tanta facilidad para ascender a los cielos, mientras que sus amigas — tal vez igual o más espirituales que 
ella - se quedaron en el limbo de la Inquisición. Igualmente, se han ignorado varias situaciones de la vida de Santa Rosa que sus biografías han querido borrar, para así trazar un camino recto hacia la santidad.

Por ejemplo, varios estudiosos han notado lo cerca que estuvo Rosa de caer también en los juicios de la Inquisición. En primer lugar, hacia 1614, Rosa tuvo un episodio en el que el doctor Juan del Castillo la interrogó por sospechas sobre sus actividades espirituales. De hecho, existe una famosa pintura que muestra tal interrogatorio, pintada por Laureano Dávila de la escuela quiteña, y que muestra de manera afable todo el asunto, mientras que, en la narración hecha por Hansen, vemos que este fue más bien un episodio bastante oscuro y temeroso para la santa. En segundo lugar, debido al proceso contra Luisa de Melgarejo hacia el año 1620, se puso en tela de juicio la santidad misma de Rosa, quien habría muerto tres años antes:

Los biógrafos y los testigos rara vez mencionan la segunda intervención de la Santa Inquisición en la década de 1620, cuando se confiscó la obra de Rosa y se comenzó un silenciamiento sistemático de los laicos religiosos cercanos a ella [...] la Inquisición confiscó los escritos de Rosa, incluyendo cartas, poesía y cuadernos espirituales. (Myers 263-264; traducción propia)

Asimismo, al enfocarnos en dos textos hagiográficos reveladores de la santa — la hagiografía de Leonardo Hansen y el testimonio de quien fue su padre espiritual, Gonzalo de la Maza-, podemos resaltar que sus prácticas espirituales eran transgresoras en muchas maneras, no solo por portar con una tradición inspirada en el misticismo de Europa, sino porque, al mismo tiempo, se le suman elementos que nos harían pensar sobre la manera como los místicos americanos también sumaban a sus prácticas religiosas otras que no necesariamente provenían de una espiritualidad católica europea. ¿Qué significaba entonces establecerse como un místico en tierras americanas? ¿Acaso habrían ciertas ventajas para aquellos o aquellas que se postulaban como las elegidas o los elegidos de Dios?

Gracias a estudios como los que ha llevado a cabo Luis Millones ("En busca de Santa Rosa: reflexiones entorno a una biografía duradera” y "Los indios de Santa Rosa: la población aborigen a través de los ojos de los bienaventurados") y un reciente artículo escrito por Stephen Hart ("The Work of the Supernatural in the Life and Work of Santa Rosa de Lima”), se ha podido trazar un mundo de Santa Rosa mucho más complejo y que comprobaría que su cercanía con las comunidades indígenas, y especialmente con su criada indígena Mariana, podría haber influenciado sus prácticas espirituales. Por ejemplo, en varios episodios narrados por sus hagiógrafos, vemos cómo Santa Rosa acude a todo tipo de maromas para poder ayunar debidamente y evitar que su familia le recrimine tales actos. En muchos de ellos, Mariana la ayuda en tales propósitos e incluso le prepara ciertos potajes que Rosa consume, y que en algunas ocasiones llama "mis gazpachos":

La prudente virgen trató de ganar a Mariana, que cuidaba de la cocina. De esta sacó, usando de su ingenio y destreza, y después de haber dado palabra de guardar silencio, que sólo guisase una torta compuesta de pedazos de pan y puñado de yerbas, cocidas con solo agua; pero sin sal ni otro condimento. (Hansen 55-56)

Así, es Mariana la que ayuda a Rosa con su voto de silencio y a crear los productos para sus ayunos; no obstante, no sabemos hasta qué punto pudo haber sido Mariana — más allá de un mero apoyo sumisouna influencia directa en la búsqueda de Rosa por nuevos alimentos, yerbas y productos exteriores con las que ayunar y poder mortificarse. ¿Con quién hablaba Rosa o con quién posiblemente compartía sus deseos por autodisciplinarse? ¿Cómo encontraba nuevas yerbas, plantas y productos para autocastigarse? El texto continúa diciéndonos:

Había llegado a los oídos de Rosa que en una selva cercana nacía cierto género de yerba muy amarga. Hizo que con secreto se la trajesen y que con ella de allí en adelante le sazonasen el potaje. Y porque no faltase provisión tan extraordinaria, plantó la yerba en su huerto, cultivándola por sus manos con gran diligencia y persuadiendo a su madre que era muy medicinal y muy provechosa [...]. Y usaba de este regalo más especialmente los viernes para gustar con Cristo en la cruz la esponja desabrida quele amargó la boca. De esta hiel y de cortezas de pan hacia un letuario, amasado con vinagre y copiosas lágrimas, al que ella llamaba mis gazpachos; porque tomaba este adobo frío y sin aplicarle a la lumbre. (Hansen 56)

Muy seguramente, tales noticias sobre yerbas de la sierra y cómo utilizarlas no podrían haber venido sino de Mariana y tal vez de otros esclavos negros o indígenas exteriores a la casa de Rosa, que a su vez eran los 
que se encargaban de traerle los productos a su casa. Especulo aquí, pero es posible que Rosa sostuviera un diálogo constante con aquellos miserables de su barrio, a los cuáles les tendía la mano, y con el mundo de los indígenas y esclavos negros que estaban en el casco urbano. Seguramente estas influencias y diálogos fueron las que la llevaron a crear una variedad de potajes y brebajes con plantas autóctonas para poder mortificarse. En ese sentido, la espiritualidad de Rosa sería queer o transcultural, ya que propondría unos espacios que iban mucho más allá de la convencional religiosidad católica.

De igual forma, sus deseos de mortificación y autodisciplina yacen en el autodesprecio del cuerpo y, como lo habíamos mencionado anteriormente, la narrativa del misticismo, la fábula mística en términos de Certeau, consistía en ocupar un lugar marginal dentro de la sociedad, para luego ser recompensado en un mundo celestial. Toda esta producción del deseo por medio del dolor, de la saciedad por medio del ayuno, podría leerse en los términos que sugiere Walker Bynum: las prácticas gastronómicas y penitenciales de las mujeres místicas se convierten en todo un sistema que podría coincidir con el rechazo al alimento que simboliza el exceso y el apetito sexual, pero, paradójicamente y bajo esa misma línea, también estas prácticas son un rechazo a esa sexualidad específica y heteronormativa del papel femenino impuesto por la familia, los religiosos y las posibles figuras masculinas, como los esposos:

Las prácticas de las mujeres con la comida frecuentemente les permitía determinar la forma de sus vidas: rechazar matrimonios indeseados, sustituir actividades religiosas por trabajos más serviles dentro de la familia, redirigir el uso de los recursos de los padres y esposos, cambiar o convertir a miembros de la familia, criticar las autoridades religiosas o seculares, y reclamar para ellas roles de enseñanza, asesoría o de corrección. (Walker Bynum 220; traducción propia)

A través de los regímenes dietarios, su deleite en comer cosas asquerosas y en sentirse plena al consumir la comunión, cuerpo de Cristo, Rosa también genera un performance de la santidad que ciertamente vuelca la lógica de los deseos y la convierte en un sujeto queer.

Dentro de esta misma línea de pensamiento, también vemos el famoso episodio de la rubia cabellera que Rosa corta como desprecio de su vanidad femenina — episodio que la madre castiga fuertemente - como una forma de escapar a un posible matrimonio y de devenir un ser indeseable para los hombres: "Ella misma se cortó hasta la raíz los cabellos, sin saberlo su madre: para que con eso no quedase materia con que pudiese o dejarse llevar o arrastrar a los hombres al matrimonio" (Hansen 11).

De alguna manera, al entrar dentro del discurso del misticismo, Rosa encuentra la manera de negarse a cumplir con los papeles tradicionales de la mujer, e incluso de encontrar un papel alternativo, como esposa de Cristo, que no podía ser cuestionado por aquellos que la rodeaban. De ese modo, muchas mujeres encontraban en el misticismo una posibilidad de movilización social, al tiempo que lograban encontrar alternativas frente a las limitadas condiciones que tenían como mujeres. En el caso de Rosa, la santa asume el papel de beata, lo cual implicaba ser una mujer libre del matrimonio, pero también libre del convento, lo que podría ser altamente peligroso para los órdenes sociales y religiosos. Así, la santa termina por vivir en una cabaña que construyó con sus propias manos y donde podía entrar en sus trances y arrobos místicos sin que nadie realmente tuviera control sobre ella. Es muy probable que, por eso mismo, llegara a ser cuestionada hacía 1614.

El lenguaje del placer y de la experiencia mística de Rosa queda completamente exacerbado a través de su muerte, que tiene lugar en la casa de Gonzalo de la Maza, y donde hay una reunión masiva de confesores, criollos, otras beatas y esclavas que van a ver ese milagro. Gonzalo de la Maza incluye dentro de su testimonio los arrobamientos que sufren Luisa de Melgarejo y una tal María Antonia frente al cadáver de Rosa. Por su parte, la mise-en-scène que nos recuenta Gonzalo de la Maza es una bastante particular: mientras las mujeres deliran, se contorsionan, balbucean, ríen, callan y repiten varias palabras frente al cuerpo difunto, hay algunos escribas que se encargan de tomar notas de lo que dicen. Miremos una de las descripciones de todo este performance que presentan estas mujeres, y que Gonzalo de la Maza nos transmite:

Y desde el principio que la dicha doña Luisa estubo en el dicho estasis estubo muy cerca della Maria Antonia muger de Juan Carrillo a quien este testigo conoce muchos dias a y tiene por muger cuydadosa y fervorosa en el servicio de nuestro señor la qual estubo asentada y sin moverse con los dedos puestos en los lavios los quales parecia memeava algunas vezes y con notada 
suspension estubo desde el principio del dicho estasis hasta que poco antes que la dicha doña Luisa saliese del que la dicha Maria Antonia se levanto de rodillas y aviendo tenido algunos impitus de naturaleza como que queria bramar levantados los brazos en cruz y doblando el cuerpo hazia atras a las espaldas de manera que casi juntava la caveza con ellas y con singular suavidad e pausa comenzo a hablar. (Millones, Una partecita del cielo 200)

Sería difícil intentar resumir de qué se tratan todas las palabras y alabanzas que las mujeres profieren, pero en general podemos decir que estas mujeres lanzan un panegírico sobre el poder de Cristo y, lo más importante, confirman que finalmente Rosa ha alcanzado el paraíso sin pasar por el purgatorio. Es así que se obtiene un testimonio delirante en el que se transmite a través de estas mujeres el estado de gozo en el que se encuentra Rosa en el cielo, lo que será un punto decisivo también para su canonización, pero será, contradictoriamente, lo que la desvíe también de su camino, ya que Luisa Melgarejo será posteriormente juzgada por sus visiones. Estos estados de arrobo demuestran la gran finalidad que tiene el misticismo: la recompensa después de toda la mortificación y desprecio de lo terrenal es la estadía en un cielo donde todo el sufrimiento queda desplazado por un placer inconmensurable y del cual se habla en términos del gusto palatal, pero en indistinta continuación con el placer sexual. La insistencia en esto trae a colación la embriaguez, la saciedad y el erotismo como a/efecto, indispensable para concebir el misticismo, que se condensa en esta imagen en la que por fin el cuerpo ausente del amado alimento se puede obtener sin limitación alguna. Cristo es el banquete-cuerpo al que ha sido invitada Rosa, y del cuál puede disfrutar sin mesura, después de toda su penitencia en la tierra.

Como si hablara directamente con Rosa, nos dice Luisa de Melgajero en sus arrobos:

Quien no te ama no te busca señor no te ama que harta estas hermana mia que satisfecha hambre que espera hartura no es hambre hambre teniais vos deste señor como le gozais si las goticas de aca eran centellas que os hazian salir de vos agora gozais de dulzuras eternas o panal dulcisimo a que embriagada estas hermana mia que embriagada estais. (Millones, Una partecita del cielo 200)

Así, hallamos en el clímax místico y la llegada al cielo una recompensa por las carencias de la vida terrenal, y también una posibilidad de desear aquello que necesariamente no se tiene (o no se es).

\section{San Martín de Porras (1579-1639) o un varón “raro” de América}

Los casos de misticismo femenino, fuera de los esquemas conventuales, fueron mucho más frecuentes que aquellos masculinos. Sin embargo, en Perú asistimos también a la proclamación del primer santo afroamericano de América, San Martín de Porras, lo que nos lleva a reflexionar también sobre las figuras místicas masculinas. Al mismo tiempo, es inevitable pensar en los elementos raciales de San Martín, nacido de una relación ilegítima entre un español (Juan de Porras) y una negra liberta de Panamá (Ana Velázquez). De allí nace un proyecto bastante ambivalente sobre la construcción de San Martín de Porras como un ejemplo de la santidad católica. Si bien se concibe al santo como un defensor de los esclavos negros y un santo de categoría universal, cuando analizamos la primera hagiografía escrita sobre este afrodescendiente - que es, además, una de las pocas publicadas en el continente americano- que salió a la luz en Lima en 1663 y posteriormente en Madrid en 1675, escrita por el dominico fray Bernardo de Medina, encontramos un proyecto bastante ambivalente, y que no necesariamente elevaba a San Martín en tanto mulato que había alcanzado un estatus divino. Al expandir más sobre la situación de los negros, mulatos, morenos y pardos en la época de San Martín, y, en general, sobre el ambiguo estatuto y funciones que tenían las personas de ascendencia africana, podremos reconstruir el valor y posicionamiento que pudo haber cobrado el santo como una representación del comportamiento fiel que esperaban los blancos de sus esclavos. Precisamente, notaremos que la primera hagiografía de San Martín a manos de fray Bernardo de Medina es un trabajo magistral en el que, a través de varios simbolismos y alegorías, se busca emblanquecer e higienizar al santo, alejándolo de las raíces maternas y africanas, y acercándolo al linaje blanco del padre, quien además fue el responsable de su educación. Así, la Vida prodigiosa del venerable siervo de Dios Fr. Martin de Porras podría leerse, como lo han sugerido en varios 
estudios Celia Cussen y Katie Walker Grimes, como un texto en el que se recrea una figura en la que el santo se desprende de su negritud y en la que, a través de su performance de la santidad blanqueada, se justifican los órdenes coloniales. El San Martín de Porras que figura en la textualidad de Medina "no subvierte el sistema esclavista; ayuda a sostenerlo" (Walker Grimes 87; traducción propia).

No obstante, encuentro también dentro del texto de Medina otro tipo de dinámicas raciales que podrían dirimir de esta única postura que sostiene que el actuar de San Martín de Porras dentro de la hagiografía consiste solamente en la confirmación de los poderes coloniales. También considero que hay espacios y silencios dentro del texto que podrían darnos una ruptura con ese San Martín que precisamente quiere imponernos Bernardo de Medina y que lo hacen una figura mucho más polémica y dinámica de lo que podría parecer. La profesión de San Martín de “barbero, enfermero y cirujano”, como lo menciona la hagiografía, no solamente es la causa de sus más grandes milagros y reconocimientos, sino que nos acerca a un contexto mucho más complejo que nos sugiere una posible cercanía de San Martín con prácticas que pudo haber aprendido de una sabiduría popular, e incluso de las prácticas de hechicería y el curanderismo que existían en la Lima de su época. Esto lo podemos apreciar en estudios ya hechos por Fernando Iwasaki ("Fray Martin de Porras: Santo, ensalmador y sacamuelas") y por Leo Garofalo ("Conjuring the Coca and the Inca: The Andeanization of Lima's Afro-Peruvian Ritual Specialists, 1580-1690”), en los que ambos expertos nos explican, por un lado, las similitudes que podían haberse dado entre los rituales de sanación provenientes de la hechicería y las prácticas de sanación de San Martín, y, por otro lado, el hecho de que para esta época los afrodescendientes podían haber encontrado maneras de incorporar los rituales ibéricos y andinos a sus fórmulas curativas.

Los sanadores negros y mulatos fueron adquiriendo varios simbolismos paradójicos dentro de la sociedad colonial: al tiempo que los esclavos negros eran considerados como una fuente de enfermedades (eran mayormente culpados por traer a la ciudad la lepra, que era signo de decadencia y pecado), también eran a menudo llamados para curar enfermedades que los médicos no lograban explicar. Como lo afirma Jouve Martín, también para el contexto de la Nueva España, "mientras muchos miembros de la élite blanca veían a los sanadores populares africanos o de ascendencia indígena como una fuente de remedios y cuidado médico, las autoridades coloniales los consideraban como un peligro para la salud pública, la ortodoxia religiosa, e incluso para la estabilidad de la colonia" (Lewis, citado en Jouve Martín 14-15). De hecho, mientras San Martín, donado del convento del Rosario, se dedicaba a sus prácticas de sanación en Lima y sus alrededores, la Inquisición sacó un edicto en 1629 en el que se condenaban todas estas prácticas supersticiosas y de hechicería relacionadas con la adivinación con habas, el encuentro de objetos perdidos, la fabricación de pócimas de amor y el uso de sueños premonitorios,

que usan asimismo, para estos y semejantes efectos, de ciertas oraciones vanas y supersticiosas, invocando en ellas a Dios nuestro Señor y a la Santísima Virgen, su Madre, y a los santos, con mezcla de otras invocaciones y palabras indecentes y desacatadas, continuandolas, por ciertos días delante de ciertas imágenes, y a ciertas horas de la noche, con cierto número de candelillas, vasos de agua, y otros instrumentos, y esperando después de las dichas oraciones, agu\#eros y presagios. (Medina 36-37)

En relación con estas posibles conexiones de San Martín con alguna especie de hechicería, la hagiografía escrita por Medina sí deja aflorar cierto halo de sospecha, o al menos confirma las preconcepciones que se tenían acerca de los afrodescendientes y sus potenciales prácticas de hechicería. Hay un episodio en el que se relata una anécdota en la que San Martín le pide con insistencia una vela a la dueña de la casa donde vivía, antes de ingresar al convento. A la mujer le parece sospechoso esto y

asomandose una noche por el resquicio de la puerta, viò, quando no lo esperava, al bien inclinado moço, que puesta la luz delante de una Imagen, postrado de rodillas, hazia fervorosa oracion, vertiendo muchas lagrimas, de que quedò la muger, sobre retratada de su temeridad, arrepentida de su culpa, pues no viò torpeza que le ofendiese, sino virtud que le edificasse. (Medina 7) 
Finalmente, el gesto de San Martín utilizando una vela y rezándole a una imagen no necesariamente confirmaba si seguía la doctrina católica o no, pues muchas de las mismas poses, gestos y rezos hechos a los santos se utilizaban también dentro de otro tipo de rituales mágicos. Además, la hagiografía no confirma cuál es la imagen a la que le reza San Martín, y así nos quedamos con una ligera duda de los posibles rituales híbridos de magia y oración que podía realizar el santo. Sin embargo, son estas prácticas de sanación bastante sospechosas las que lo llevarán a adquirir su fama, a pesar de sus orígenes modestos, lo que lo conducirá incluso a tener roces con las personas más importantes de su sociedad.

De hecho, si vemos a la figura que más pudo influir para su caso de canonización, fray Cipriano de Medina (1594-1664) - a quién San Martín curó y protegió-, notamos que tal fraile estaba muy bien conectado y que fue un catedrático de la Universidad de San Marcos y calificador de la Inquisición (Cussen 52). Además, fray Cipriano de Medina era sobrino del recién nombrado obispo de Nueva España, Feliciano de la Vega a quien San Martín de Porras también curó-, y al parecer era pariente lejano también del mismo Bernardo de Medina (Cussen 23).

De allí que también como efecto de este doble discurso entre su completa humildad y su gran influencia, gracias a sus conocimientos curativos, veamos una insistencia por parte de Bernardo de Medina para intitular al Varón de Dios como un sujeto raro, o cuyas acciones eran consideradas como "raras"; para cerrar una anécdota sobre San Martín queriéndose vender como esclavo, nos dice Bernardo de Medina: "Cerremos este capítulo con llave de oro del sufrimiento raro en sus trabajos, y adversidades” (Medina 17). La rareza en este caso la podemos considerar en el contexto como aquello que está cercano a lo prodigioso o a lo maravilloso, como sería el caso de la santidad subalterna en América. Al mismo tiempo, encontraríamos en el uso de la palabra rareza una connotación de algo que ciertamente no encaja con el pensamiento común, o también algo que podría acercarlo a un sentido similar a lo que podría ser lo queer: un tercer espacio, un individuo fugado que vive y se desplaza constantemente en las zonas grises de la indefinición. ¿Cómo este donado del convento del Rosario encuentra tanto gusto y placer en autodenominarse esclavo y en arrojarse en los lugares más inmundos del convento, que ciertamente era una de las peores situaciones por las que podía pasar un ser humano?

Aparte de este sentido de lo queer racializado que crea el misticismo de San Martín, y en el que se propone un performance o simulación del esclavismo, podríamos también asociarlo con un elemento queer sexual. En parte, lo queer tendría que ver con las cualidades oximorónicas de castidad-erotismo místico que condicionan la santidad, pero también encuentro ciertas prácticas de San Martín que lo podrían asociar con cierto homoerotismo. Así, encontramos a un San Martín que a menudo se autodisciplina desnudo, y que además comparte sus experiencias místicas con otros hombres religiosos que son sus amigos: el también famoso santo Juan Macías (1585-1645) y un tal Francisco de los Descalzos. Las prácticas compartidas pueden leerse en un registro de homoerotismo, no solamente inherente a las prácticas compartidas y extremas del misticismo, sino también a la relación que se establece entre el místico desbordado por la figura de Cristo, que unas veces es muy varonil y otras es femenino. Recordemos entonces que en el misticismo masculino muchas veces los hombres se proponían como "las mujeres", para que la relación de unión fuera posible con Cristo, aunque, al tiempo, había también una figuración de Cristo como una figura femenina.

El discurso místico dentro de la hagiografía evidencia que la penitencia extrema deja como efecto un tipo de placer "sadomasoquista" y encontramos a San Martín en sangrientas escenas en las que se convierte en una máquina de sufrimiento que es sorprendente y escalofriante, en plena exhibición oximorónica de un cuerpo que encuentra en la violencia una forma de placer:

Al desnudarse, pues, para la segunda disciplina, como las llagas de la primera quedavan vertiendo sangre, tenía pegada la túnica a las carnes, y quitándosela sin lástima y con violencia, se renovavan las heridas, sintiendo en este martirio el Siervo de Dios uno de los mayores tormentos que padeció el Salvador en el Calvario. El regalo y remedio de que usava, era desnudarse todo el cuerpo, y sin reservar parte al dolor, se heria nuevamente con un latigo, con tan estraño rigor, que bañado en arroyos de sangre por los surcos que los açotes formavan, regavan la tierra del Capitulo, acompañando al sonido de la disciplina, lagrimas de los ojos, y a estas vozes lastimeras que repetia, diziendo: "Misericordia, Señor, misericordia". (Medina 19) 
También podemos ver las instancias donde San Martín se reúne en varias ocasiones con fray Francisco de los Descalzos para hacer sus prácticas místicas juntos:

\begin{abstract}
Abraçandose amorosamente, se entraron a recrear en la huerta; y como los Siervos de Dios no pierden tiempo, lugar ni ocasion para el servicio de tan gran Señor, Monarca universal de lo criado, el recreo y divertimiento que tuvieron, fue poner en un arbol de la huerta la Imagen de un santo Crucifixo [...]. Començaron a orar tan fervorosamente, que todo era lamentos solloços y suspiros, regando con abundantes lagrimas el suelo [...]. A la oracion, y llanto acompaño tambien la diciplina, y de este exercicio durado mucho tiempo, se vistieron y dieron gracias à Dios de la gustosa tarde que avian passado, deseando repetir la recreación muchas vezes, que como los hijos de Belial suelen juntarse para ofender con sus delitos al Cielo, se avienen tambien los hijos del Señor para servirle. (Medina 22)
\end{abstract}

Desde una lectura de lo queer y que aludiría a ciertos elementos sexuales que se perciben en el misticismo, podríamos decir que existe un cierto homoerotismo en torno al misticismo que ambos hombres practican. No deja de sorprender el hecho de que todas estas disciplinas y oraciones las hacían en plena desnudez ("se vistieron y dieron gracias a Dios"), lo que podría perfectamente ser una escena del llamado pecado nefando, o cualquier otro tipo de ritual heterodoxo que podía implicar actos sexuales. Si bien podríamos estar seguros de que la intencionalidad de Medina es transmitir la voluntad férrea de los devotos y la pureza con la que los dos hombres alaban a su Dios (la desnudez podría ser un símbolo de la entrega completa y de la castidad), también podríamos decir que el discurso místico es uno que excede a cualquier control del autor. De allí, que se transmitan unos significados que sobrepasan las intencionalidades mismas de Medina y que se refieren a los sentidos queer del misticismo. Al fin y al cabo, el mismo texto, aunque de forma involuntaria, pone en peligro estas prácticas místicas de San Martín cuando las compara con aquellas que los hijos de Belial (el demonio) podrían practicar, de modo que prácticas similares podrían llevarse a cabo, ya fuera para invocar a Dios o al demonio; lo que contaba era realmente hacia quién estaban dirigidas. Así, tasamos también estos límites y ambivalencias en los que se permitían unos cuerpos desnudos que se disciplinaban mutuamente como una instancia de la producción de lo queer dentro del misticismo masculino.

De acuerdo con las dos figuras de santidad limeñas que hemos venido analizando, considero que este estudio podría ser la base de un análisis mucho más integral e intensivo desde varias perspectivas posmodernas de las santidades y sus prácticas en los territorios de la colonia española en América. Es primordial para los estudios coloniales y de género interesarse en este tipo de narrativas de figuras de devoción, ya que a través de estos modelos de santidad encontramos concentradas varias simbologías y narrativas sociales, culturales y religiosas de la Colonia; la especificidad textual (y sexual) de la hagiografía nos permite analizar y evaluar muchas de las tensiones que existían en el mundo colonial, pero, al mismo tiempo, notar sus ambivalencias y posibilidades de significación. Considero que lo queer como herramienta crítica permite explicar de mejor manera las texturas oximorónicas y ambivalentes de las que estaba hecho el misticismo, sus identidades y sus prácticas dentro de las hagiografías. El hecho de que lo queer sea en sí mismo un concepto elástico y que pone entre comillas lo natural, nos ayuda también a entender la polivalencia del misticismo y a considerar sus múltiples características dentro de un contexto colonial. Al fin y al cabo, tanto lo queer como lo místico son "la red abierta de posibilidades, vacíos, superposiciones, disonancias y resonancias, tiene[n] fallos y excede[n] el significado cuando los elementos constituyentes del género o sexualidad de alguien no están hechos (o no pueden estar hechos) para significar de forma monolítica" (Sedgwick, citado en Lochrie 180). La autodisciplina excesiva en el cuerpo desnudo de San Martín de Porras, o la mutilación del cabello de Santa Rosa con miras a lograr un matrimonio místico con la figura del niño Jesús, son todas expresiones de una sexualidad y subjetividad-otra, y de unas manifestaciones místico-queer que demuestran la heterogeneidad de valores ambivalentes de lo que podía significar la sexualidad expresada en términos de la santidad, y que, por cierto, se oponían a otros valores de la heterosexualidad normativa. 
Al final, comprobamos que esta identidad performativa de la santidad ofrecía posibilidades de vida que de otro modo eran casi imposibles: la opción de una independencia y de renuncia al matrimonio o al convento que le da el misticismo a Santa Rosa de Lima; cierta movilidad social como la que alcanzó en Lima San Martín de Porras. Toda esta fluidez, porosidad y maleabilidad del misticismo generaba un contradiscurso dentro de las estructuras coloniales, lo que nos ayudaría a replantear una noción anquilosada sobre la colonia y su funcionamiento. Considero que el trabajo que queda por hacer no solo con las hagiografías coloniales, sino también con otros materiales relacionados con la construcción de la santidad es vasto y mi pretensión, entonces, fue la de ofrecer un camino de análisis a través de un misticismo queer que "confunde estados, ignora asuntos, no conoce fronteras" (Clairvaux, citado en Lochrie 186).

\section{Referencias}

Certeau, Michel de. La fábula mistica: siglos XVI-XVII. Universidad Iberoamericana, 2010.

Cussen, Celia. Martín de Porres, santo de América. IEP, 2017.

Estenssoro, Juan Carlos. Del paganismo a la santidad. IFEA / PUPC, 2003.

Garofalo, Leo. "Conjuring the Coca and the Inca: The Andeanization of Lima's Afro-Peruvian Ritual Specialists, 1580-1690”. The Americas, vol. 63, n. ${ }^{\circ} 1$, julio de 2006, pp. 53-80.

Hansen, Leonardo. Vida admirable de Santa Rosa de Lima: patrona del nuevo mundo. Vergara, tipógrafo del Santísimo Rosario, Real Seminario, 1895.

Hart, Stephen. "The Work of the Supernatural in the Life and Work of Santa Rosa de Lima”. From the Supernatural to the Uncanny, editado por Stephen Hart y Zoltán Biedermann, Cambridge Scholars Publishing, 2017.

Iwasaki, Fernando. "Fray Martin de Porras: Santo, ensalmador y sacamuelas". Historias, vol. 30, abril-septiembre de 1993, pp. 107-126.

"Mujeres al borde de la perfección: Rosa de Santa María y las alumbradas de Lima”. Una partecita del cielo. La vida de Santa Rosa de Lima narrada por Dn. Gonzalo de la Maza, a quien ella llamaba padre. Editorial Horizonte, 1993, pp. 71-110.

Jaffary, Nora. False Mystics: Deviant Orthodoxy in Colonial Mexico. University of Nebraska Press, 2004.

Jagose, Annamarie. Queer Theory: An Introduction. New York University Press, 1996.

Jouve Martín, José R. The Black Doctors of Colonial Lima: Science, Race, and Writing in Colonial and Early Republican Peru. McGill-Queen's University Press, 2014.

Lochrie, Karma. "Mystical Acts, Queer Tendencies". Constructing Medieval Sexuality, editado por Karma Lochrie, Peggy McCracken y James A. Schults, University of Minnesota Press, 1997, pp. 180-200.

Medina, Bernardo de. Vida prodigiosa del venerable Siervo de Dios Fr. Martin de Porras, natural de Lima, de la Tercera Orden de N.P Santo Domingo. Imprenta de Domingo García, 1675.

Millones, Luis. "En busca de Santa Rosa: Reflexiones en torno a una biografia duradera”. Bulletin of the National Museum of Ethnography of Osaka, vol. 14, n. ${ }^{\circ} 4,1990$, pp. 891-907.

“Los indios de Santa Rosa: la población aborigen a través de los ojos de los bienaventurados". Senri Ethnological Studies, vol. 33, 1992, pp. 103-112.

------. Una partecita del cielo. La vida de Santa Rosa de Lima narrada por Dn. Gonzalo de la Maza, a quien ella llamaba padre. Editorial Horizonte, 1993.

Myers, Katherine Ann. "Redeemer of America: Rosa de Lima (1586-1617), The Dynamics of Identity and Canonization". Colonial Saints: Discovering the Holy in the Americas, editado por Allan Greer y Jodi Bilinkoff, Routledge, 2003, pp. 251-276.

Osorio, Alejandra. "El callejón de la soledad: Vectors on Cultural Hybridity". Spiritual Encounters: Interactions Between Christianity and Native Religions in Colonial America, editado por Nicolas Griffith y Fernando Cervantes, The University of Birmingham Press, 1999, pp. 198-229. 
Walker Bynum, Caroline. Holy Feast and Holy Fast: The Religious Significance of Food to Medieval Women. University of California Press, 1987.

Walker Grimes, Katie. “The Racialized Humility of Saint Martín de Porres". Fugitive Saints: Catholicism and the Politics of Slavery. Fortress Press, 2017, pp. 75-90.

\section{Notas}

* $\quad$ Artículo de investigación

\section{Licencia Creative Commons CC BY 4.0}

Cómo citar este artículo: Espitia Durán, Pilar. "Figuras de santidad en el virreinato de Perú: lo queer, la alteridad". Cuadernos de Literatura, vol. 25, 2021. https://doi.org/10.11144/Javeriana.cl25.fsvp 